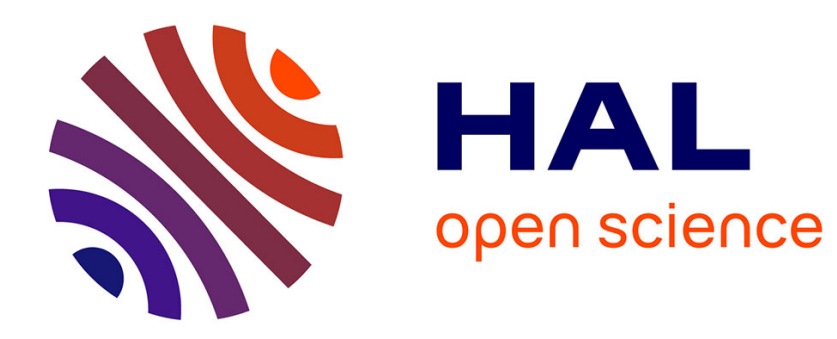

\title{
Cathodoluminescence study of Zn doped Gan
}

M. Boulou, G. Jacob, D. Bois

\section{To cite this version:}

M. Boulou, G. Jacob, D. Bois. Cathodoluminescence study of Zn doped Gan. Revue de Physique Appliquée, 1978, 13 (11), pp.555-563. 10.1051/rphysap:019780013011055500 . jpa-00244485

\section{HAL Id: jpa-00244485 https://hal.science/jpa-00244485}

Submitted on 1 Jan 1978

HAL is a multi-disciplinary open access archive for the deposit and dissemination of scientific research documents, whether they are published or not. The documents may come from teaching and research institutions in France or abroad, or from public or private research centers.
L'archive ouverte pluridisciplinaire HAL, est destinée au dépôt et à la diffusion de documents scientifiques de niveau recherche, publiés ou non, émanant des établissements d'enseignement et de recherche français ou étrangers, des laboratoires publics ou privés. 


\title{
CATHODOLUMINESCENCE STUDY OF Zn DOPED GaN (*)
}

\author{
M. BOULOU, G. JACOB (**) and D. BOIS $(* * *)$ \\ Laboratoires d'Electronique et de Physique Appliquée \\ 3, avenue Descartes, 94450 Limeil-Brévannes, France
}

(Reçu le 24 juin 1978, accepté le 18 août 1978)

\begin{abstract}
Résumé. - Nous présentons une analyse des propriétés de luminescence du GaN dopé $\mathrm{Zn}$. Quand la concentration de $\mathrm{Zn}$ augmente, on observe en cathodoluminescence quatre bandes d'émission : bleu $(2,85 \mathrm{eV})$, vert $(2,5 \mathrm{eV})$, jaune $(2,2 \mathrm{eV})$ et parfois rouge $(1,9 \mathrm{eV})$.

De l'analyse de la luminescence en fonction de la température de l'injection, et du temps, les émissions bleue, verte et jaune s'interprètent bien dans un modèle de transition de paire avec un important couplage phonon. Un modèle de recombinaison est discuté d'après les variations de l'intensité des émissions en fonction du niveau d'injection.
\end{abstract}

\begin{abstract}
The luminescence properties of $\mathrm{GaN}$ doped with $\mathrm{Zn}$ are reported. As the $\mathrm{Zn}$ concentration increases four different emissions are found using cathodoluminescence : blue $(2.85 \mathrm{eV})$, green $(2.5 \mathrm{eV})$, yellow $(2.2 \mathrm{eV})$ and sometimes red $(1.9 \mathrm{eV})$. Through the analysis of the influence of temperature, injection and time dependence, the blue, green and yellow emissions are found to fit a pair transition model, with a strong phonon coupling. The recombination model is discussed in view of the observed variation of the emission intensities versus injection level.
\end{abstract}

1. Introduction. - Several authors have reported about electroluminescence in GaN [1-6]. As a rule $\mathrm{Zn}$ doping is found to provide the better results.

We have previously reported about the growth parameters governing the $\mathrm{Zn}$ incorporation in $\mathrm{GaN}$, and about the performances of electroluminescence devices prepared in our laboratory [7-10]. The structure was $m-\Pi-n$ with a very thin $\Pi$ layer in which electroluminescence was excited by electron injection out of the $n$ region, and field assisted generation of holes. Electroluminescence in the blue, green and yellow was obtained.

In spite of these interesting electroluminescence properties of $\mathrm{GaN}: \mathrm{Zn}$, few convergent experimental results are available about the characteristics of the $\mathrm{Zn}$ associated luminescence. Blue luminescence is generally observed [11-18]. Several recombination processes have been discussed for this blue emission : donor-acceptor, free-bound transitions with band tailing effects, intercentre recombination. But the experimental results obtained in different laboratories are often contradictory, in particular for the shift of the band versus parameters such as tempera-

(*) This work has been supported by DGRST.

(**) With La Radiotechnique Compelec, Route de la Délivrande, 14001 Caen Cedex (France).

$\left({ }^{* * *}\right)$ With INSA Lyon, 20, avenue A.-Einstein, 69621 Villeurbanne (France). ture, excitation level... etc. So, no definitive conclusion emerges.

In this work, the properties of this blue emission has been carefully analysed together with those of the green and yellow emissions which have been shown to appear at higher $\mathrm{Zn}$ concentration in a previous paper [19].

2. Experimental background. -2.1 CRYSTAL GROWTH AND DOPING. - The GaN layers studied in this work have been grown on sapphire substrates (0001) using the vapour phase method described previously $[8,19,20]$ : the basic reaction is

$$
\mathrm{GaCl}+\mathrm{NH}_{3} \rightarrow \mathrm{GaN}+\mathrm{HCl}+\mathrm{H}_{2}
$$

the deposit temperatures are between $950{ }^{\circ} \mathrm{C}$ and $970^{\circ} \mathrm{C}$; nitrogen is used as vector gas in the reactor ; and $\mathrm{GaCl}$ is produced by the reaction of $\mathrm{HCl}$ on a gallium source. Zinc is introduced through evaporation from. a solid source. The temperature of $\mathrm{Zn}$ source, and the free $\mathrm{HCl}$ partial pressure are used to control the $\mathrm{Zn}$ incorporated in the layers.

Undoped GaN layers are $n$ type with $n \simeq 10^{19} \mathrm{~cm}^{-3}$. $\mathrm{Zn}$ doping leads to a decrease of the electron concentration and to high resistivity layers.

2.1 Measurement of the $\mathrm{Zn}$ CONCENTRation. The total concentration of $\mathrm{Zn}$ incorporated in the 
layers has been determined by $\mathrm{X}$ ray fluorescence spectroscopy. Simultaneous measurements of the $K_{\alpha}$ lines of $\mathrm{Zn}$ and $\mathrm{Ga}$ (taken as reference) were used. Concentration between $10^{18}$ and $7 \times 10^{20} \mathrm{~cm}^{-3}$ have been measured. The homogeneity of the layers have been checked using a microprobe.

\subsection{CATHOdoluminesCENCE MEASUREMENTS. - The} mean characteristics of the electron beam are : accelerating voltage 2 to $30 \mathrm{kV}$, current 0.1 to $100 \mu \mathrm{A}$, and spot diameter $\sim 300 \mu \mathrm{m}$.

The detection system includes a grating monochromator and a 56-TVP (RTC) photomultiplier. Except for efficiency measurement, the spectra are not corrected for the spectral sensitivity of this system.

Modulation of the electron beam for time response analysis is achieved by beam deflection. The rise and decay times of the pulses are less than $1 \mathrm{~ns}$, their width may be choosen between $15 \mathrm{~ns}$ and $100 \mu \mathrm{s}$ with a repetition rate between $10 \mathrm{~Hz}$ and $1 \mathrm{MHz}$. The signal is amplified and analysed in a boxcar integrator whose gate width is $1 \mathrm{~ns}$. The experimental time resolution is about $3 \mathrm{~ns}$. The sample temperature can be regulated between $5 \mathrm{~K}$ and $400 \mathrm{~K}$.

3. Influence of the zinc concentration. - Figure 1 shows the cathodoluminescence spectra at $300 \mathrm{~K}$ of six samples having widely different $\mathrm{Zn}$ concentrations.

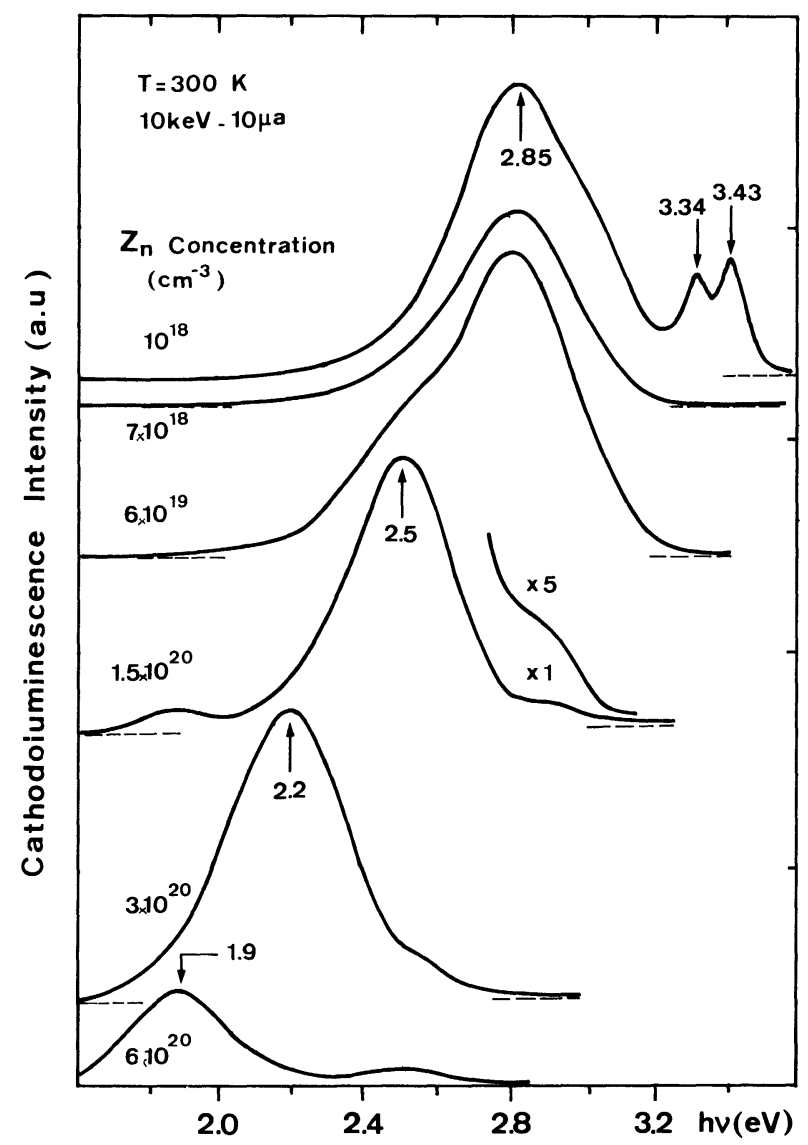

FIG. 1. - Cathodoluminescence (CL) spectra at $300 \mathrm{~K}$ for six samples with different $\mathrm{Zn}$ concentrations.
At low $\mathrm{Zn}\left(\leqslant 10^{18} \mathrm{~cm}^{-3}\right)$, two small lines at 3.34 and $3.43 \mathrm{eV}$ appear. Similar lines have already been observed [11, 21-24] and assigned to the recombinations of an exciton bound to a neutral acceptor $\mathrm{Zn}_{\mathrm{Ga}}$ with its phonon replica. The blue band at $2.85 \mathrm{eV}$ has been observed by many authors $[1,11$, $15,25-27]$ it does not appear in undoped samples, so it can attributed to zinc doping as generally assumed. It is visible in a large $\mathrm{Zn}$ range : typically from $10^{18}$ to $10^{20} \mathrm{~cm}^{-3}$, and the corresponding external efficiency are more than $1 \%$. This measurement has been performed using a GaN calibrated sample [19], it is in good agreement with values reported by Ilegems [25] and Pankove [28].

For $\mathrm{Zn} \gtrsim 10^{19} \mathrm{~cm}^{-3}$, a green band at $2.5 \mathrm{eV}$ appears. It decreases above several $10^{20} \mathrm{~cm}^{-3}$. The corresponding luminescence efficiency is much less than for the blue band : typically $\sim 0.1 \%$. At higher $\mathrm{Zn}$ concentrations, a yellow band at $2.2 \mathrm{eV}$, and a red one at $1.9 \mathrm{eV}$ appear. Their efficiencies have been evaluated about $0.1 \%$ and $0.01 \%$ respectively.

Luminescence ranging from red to blue has been reported before in $\mathrm{Zn}$ doped $\mathrm{GaN}$ [1, 4, 27, 29], but the conditions for observing each colour were not determined. Moreover, it was not clear whether these different colours were generated by one very large band, by the shift of a narrower band and by several bands, the spectra in figure 1, show that four distinct luminescent bands do exist. This assessment will be strongly supported by the temperature analysis. The magnitude of each band is chiefly determined by the $\mathrm{Zn}$ concentration in the layer. So, one can assume that $\mathrm{Zn}$ introduces several different centres in $\mathrm{GaN}$ depending on the $\mathrm{Zn}$ concentrations.

Ilegems et al. [11, 30], consider that $\mathrm{Zn}$ on Ga site forms a simple acceptor at $190 \mathrm{meV}$ above the valence band. Such level cannot account for any of the four bands described here. Pankove [31] suggests that $\mathrm{Zn}$ may refill the nitrogen vacancies $\left(V_{\mathrm{N}}\right)$ which are probably responsible for the $\mathrm{n}$ type conductivity in undoped GaN. This would lead to a triple acceptor and might explain three luminescent bands, but the large difference between the respective magnitude of the bands should be difficult to understand if a unique triple centre is involved. Considering the very large $\mathrm{Zn}$ and $V_{\mathrm{N}}$ concentrations, one can assume that complexes are formed between $\mathrm{Zn}$ atoms and nitrogen vacancies : for instance complex involving one or more $\mathrm{Zn}$ atoms according to the $\mathrm{Zn}$ concentration. More generally, one can imagine recombination at nitrogen vacancies interacting with one, two or three $\mathrm{Zn}$ atoms.

4. Study of the temperature behaviour. - 4.1 INTENSITY VARIATIONS. - The intensity of each luminescence band increases at low temperature, but with different rates according to each band. This leads to a change of the emitted colours versus temperature as shown in figure 2 : at room tempera- 
ture, in this particular sample yellow emission is almost visible alone, while the green band and the blue ones dominate in the ranges $200 \mathrm{~K}-80 \mathrm{~K}$ and $80 \mathrm{~K}-5 \mathrm{~K}$ respectively. It is also clear from figure 2 that this colour change does not come from the shift of a unique band, but from the distinct ones. This supports the assessement that several levels are present.

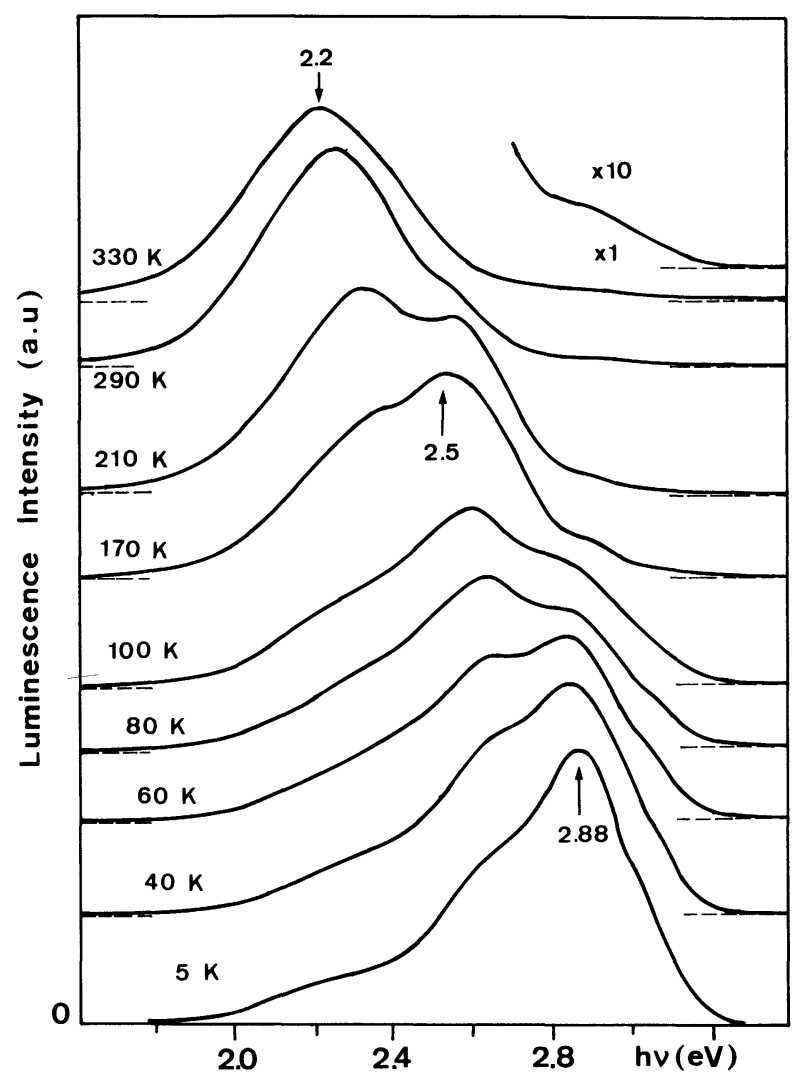

FIG. 2. - CL spectra at different temperatures of a sample with $\mid \mathrm{Zn}=1.5 \times 10^{20} \mathrm{~cm}^{-3}$. The excitation conditions are $: 10 \mathrm{keV}$, $10 \mu \mathrm{A}$ and all spectra are recorded with the same sensibility $\times 1$.

In some samples, depending on the zinc concentration, one band dominates in a large temperature range, thus allowing the analysis of its specific characteristics. Figure 3 shows the spectra recorded for isolated blue and green band between $77 \mathrm{~K}$ and $330 \mathrm{~K}$.

The corresponding integrated intensities have been plotted versus $10^{3} \mathrm{~T}^{-1}$ in figure 4 . Luminescence quenching is visible in the high temperature region. From the slopes of the two straight lines one deduces the corresponding thermal activation energies : $E_{\mathrm{A}}=0.33 \pm 0.07 \mathrm{eV}$ for the blue band and

$$
E_{\mathrm{A}}=0.8 \pm 0.1 \mathrm{eV}
$$

FIG. 4. - Semi-logarithmic recording of integrated luminescence intensity $v s$ reciprocal temperature $\left(10^{3} T^{-1}\right)$ for blue and green bands.

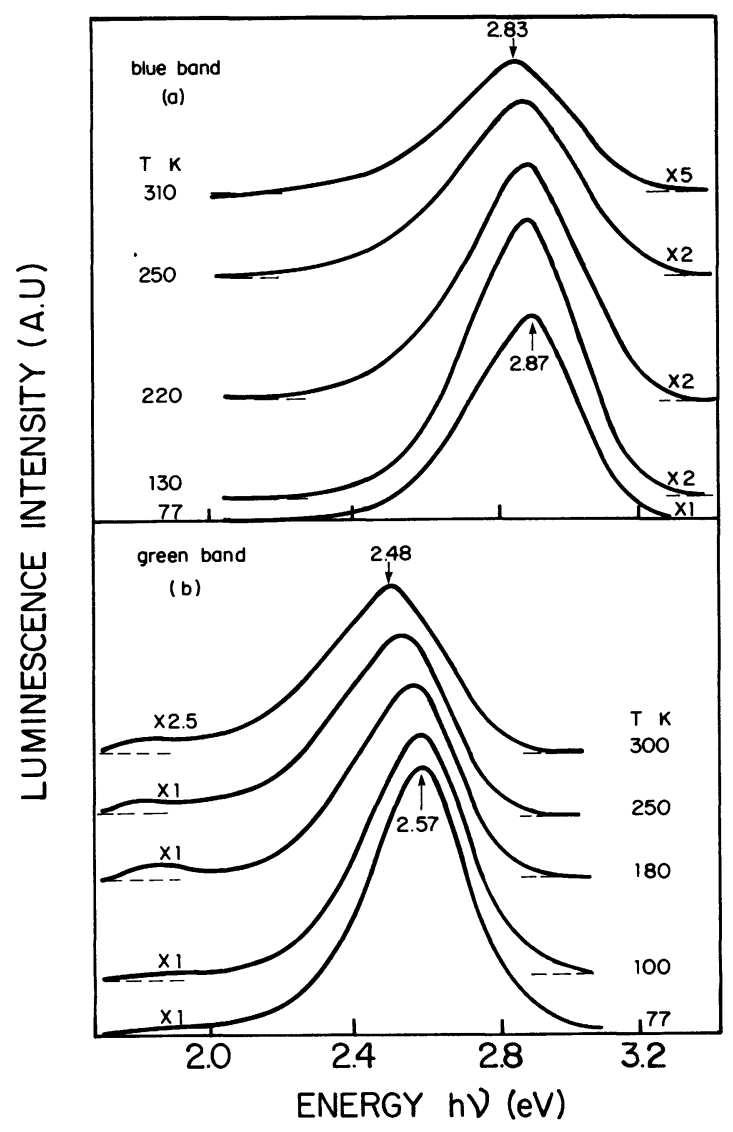

FIG. 3. - Temperature dependence of the blue $(3 a)$ and green (3b) bands.

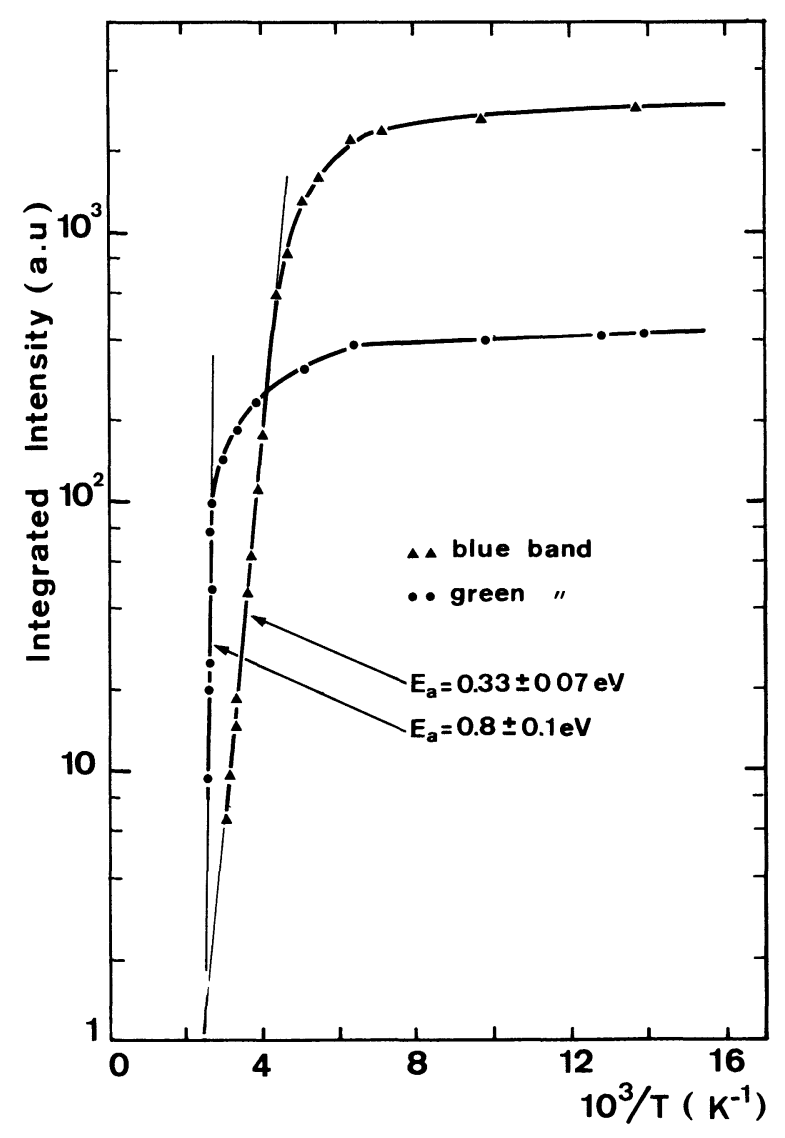


for the green one. This result for the blue band is in good agreement with values previously reported by Ilegems et al. [25] and Pankove [28], i.e. 0.3, $0.4 \mathrm{eV}$. The infrared quenching experiments performed by Ejder and Grimmeiss [15], provides a threshold energy near $0.48 \mathrm{eV}$ for the blue band. This value is slightly different from the thermal activation energy just found, but this can be explained by lattice coupling effect as discussed below.

4.2 SHIFT OF THE LUMINESCENCE PEAKS. - As visible in figure $3 a$ slight shift of each band towards higher energies arises as the temperature is lowered. We have plotted in figure 5 these peaks energy variations together with that of the energy gap of $\mathrm{GaN}$ as reported by Lagerstedt and Monemar [23]. These variations are very close together, so transition between levels associated with conduction band and valence band respectively are probable.

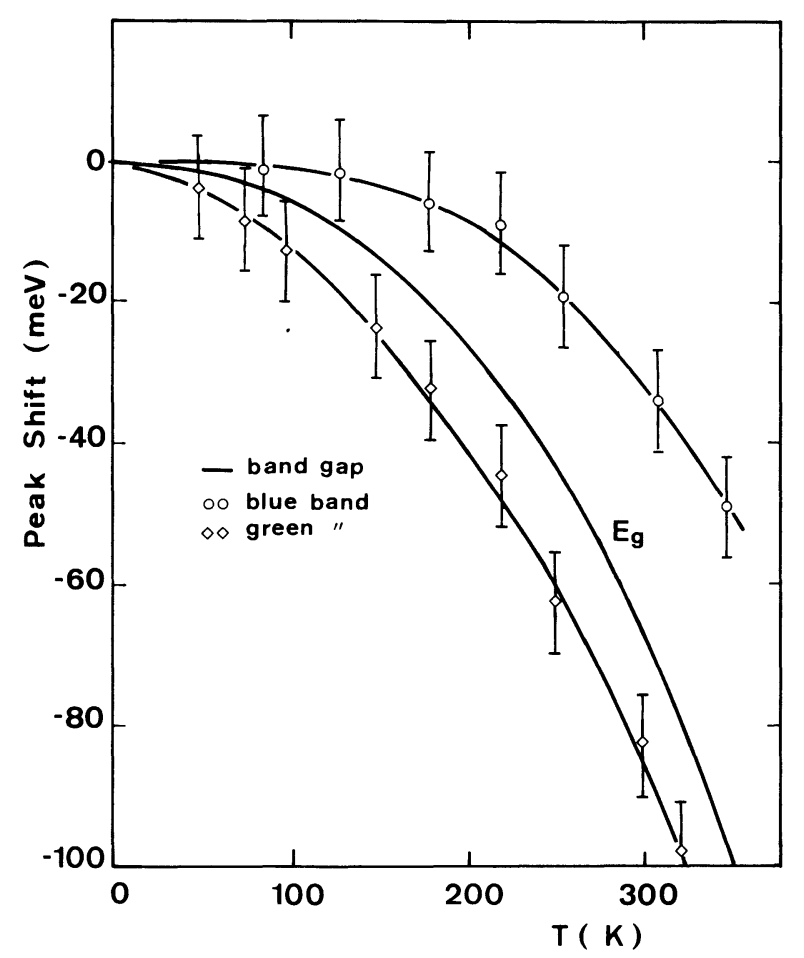

FIG. 5. - Peak shift $v s$ temperature for blue and green luminescence. The solid curve shows the band gap variation obtained with the relation [23]

$$
E_{\mathrm{g}(\mathrm{eV})}=3.503-\frac{5.08 \times 10^{-4} T^{2}}{992-T} .
$$

4.3 SHAPE OF THE EMISSION BANDS. - No fine structures have been observed even at $5 \mathrm{~K}$. At all temperatures, the luminescence bands look like gaussian with a significant increase of the half height width when the temperature rises.

This may be explained by phonon coupling, so we have plotted in figure 6 the variations of these half

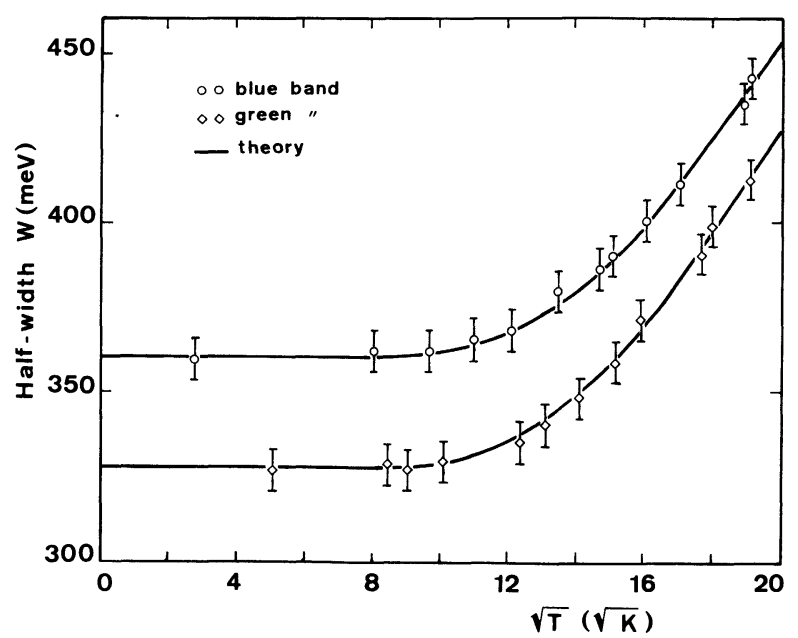

FIG. 6. - Variation of the half-width $W v s T^{1 / 2}$ for blue and green emission. The theorical curves are a plotting of equation (1) with $\hbar \omega_{\mathrm{q}}=45 \mathrm{meV}$ (blue band) and $50 \mathrm{MeV}$ (green band).

height width $W$ versus $T^{1 / 2}$ for the blue and green bands. The experimental data fit the classical law [32] :

$$
W(T)=W(0)\left[\cot \mathrm{h} \frac{\hbar \omega_{\mathrm{q}}}{2 k T}\right]^{1 / 2}
$$

where $W(0)$ is the half width at $0 \mathrm{~K}, \hbar \omega_{\mathrm{q}}$ the vibrationnal energy and, $k$ is Boltzmann's constant.

The experimental value of the vibrationnal energy $\hbar \omega_{\mathrm{q}}$ is between 45 and $50 \mathrm{meV}$ for both centres. The optical phonon energies in $\mathrm{GaN}$ are : $\hbar \omega_{\mathrm{LO}}=90 \mathrm{meV}$ and $\hbar \omega_{\mathrm{TO}}=66 \mathrm{meV}[33,34]$ so one may assume that resonant localized modes are involved.

Finally, it turns out that the width of the luminescence bands and their variations versus temperature is well explained by phonon coupling effect, and could be described using a configuration curve model. Such model implies relaxation effect i.e. : phonon emission associated with each electron transition. So, the zero phonon lines should lie on the high energy side of each emission band, i.e. : above $3 \mathrm{eV}$ for the blue band and $2.8 \mathrm{eV}$ for the green ones.

These considerations are in good agreement with the photoexcitation threshold reported by Ejder and Grimmeiss [15] : $3.17 \mathrm{eV}$ for the blue emission at $78 \mathrm{~K}$.

Obviously, from this analysis, one cannot rule out that other mechanisms also contribute to the slope of the luminescence bands. For instance, in such highly doped materials, band tailing effects must exist. These influences enter in the factor $W(0)$ : the half height width at $0 \mathrm{~K}$ (cf. relation (1)).

\section{Recombination kinetics. - 5.1.ROOM TEMPERA-} TURE. - Transient cathodoluminescence response have been analysed using long excitation pulses $(20 \mu \mathrm{s})$ in such a way that the surface recombinations do not affect the shape of the decay curves [35]. 
The kinetics of the four luminescence bands described above are found to be very slow compared to that of near edge transitions, as observed in gallium nitride undoped, which is typically a few ns [31, 36]. The rise and decay times are found equal.

Figure 7 shows the shape of the decays at $300 \mathrm{~K}$ of the blue, green and yellow bands on a semi-logarithmic scale. The decay times $\tau$ are always in the order $(\tau$ (yellow) $>\tau$ (green) $>\tau$ (blue)), but the values differ slightly from one sample to another : for instance the lifetime for the blue band is found between $0.5 \mu$ s and $0.9 \mu \mathrm{s}$. The decay curves, as visible in figure 7 are non exponential.

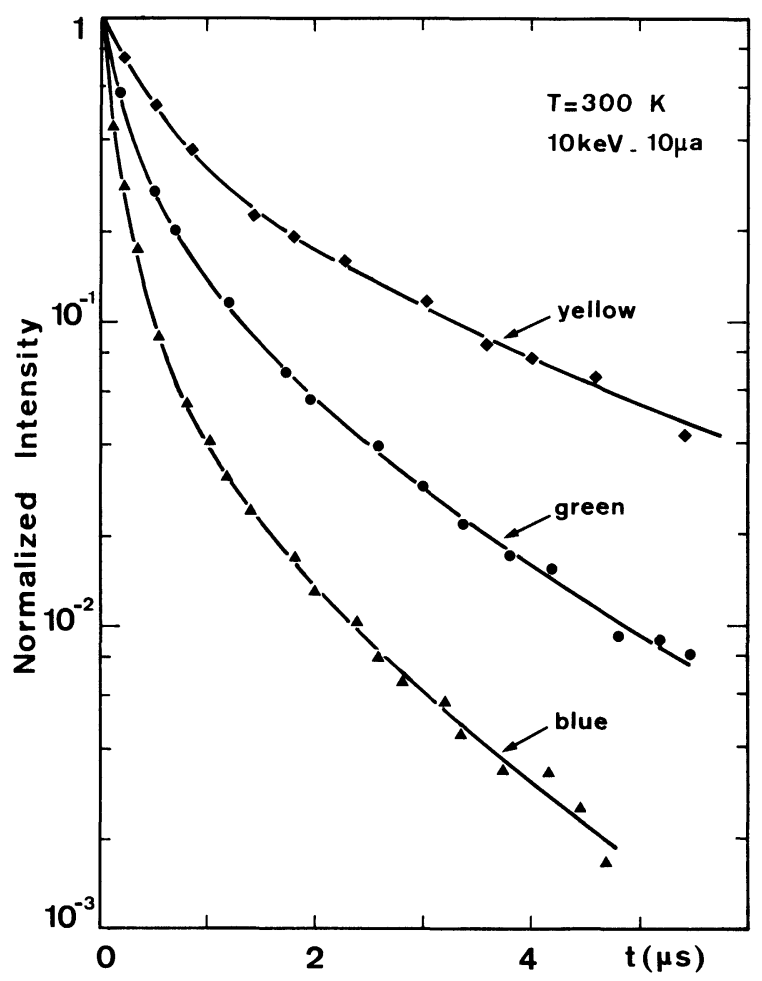

FIG. 7. - Shape of the luminescence decay time at $300 \mathrm{~K}$ of the blue, green and yellow bands on a semi-logarithmic scale.

5.2 Low TEMPERATURE. - Figure 8 shows time resolved spectra (T.R.S.) of the blue and green bands at $77 \mathrm{~K}$. When the delay increases, the emission peaks shift towards lower energy. The total shift for $2 \mu \mathrm{s}$ is about $50 \mathrm{meV}$. As for the room temperature data, the decays for each band are non exponential (Fig. 9).

Thus, one cannot consider the emissions to be due to simple transitions between well defined levels. Either pair transitions or band tailing effects are involved.

The time constants increase when the temperature is lowered. In order to illustrate this point for the blue emission, we have plotted in figure 10 the reverse of the time constant, deduced from the tangent of the decay curve in the long time region versus $10^{3} T^{-1}$. This curve provides an activation energy about $0.3 \mathrm{eV}$

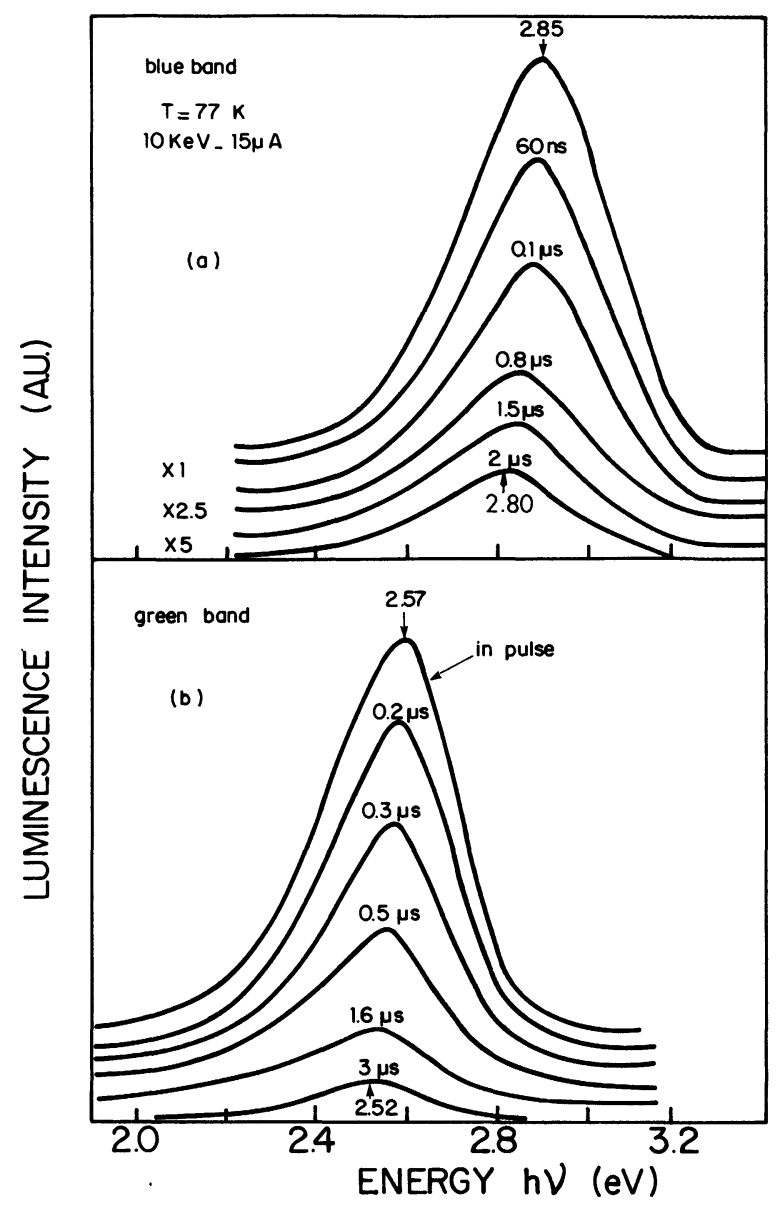

Fig. 8. - Time resolved spectra at low temperature $(77 \mathrm{~K})$ for blue $(a)$ and green $(b)$ bands.

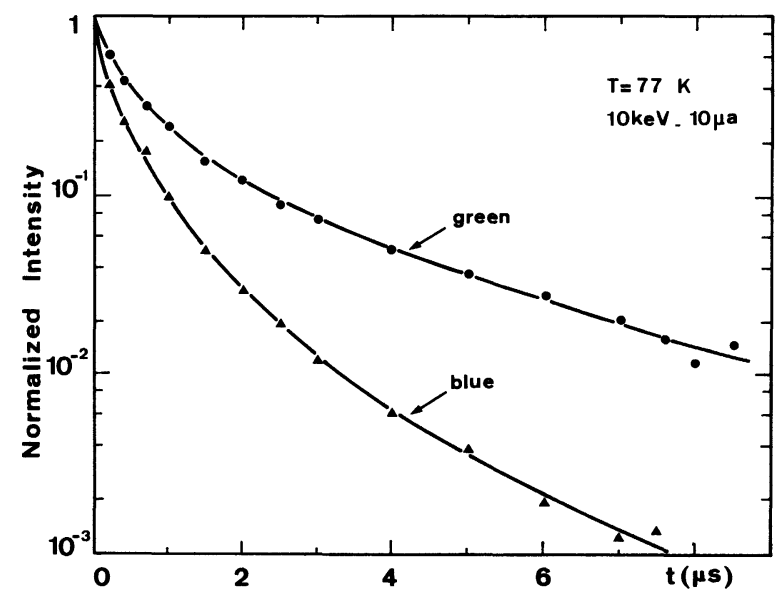

FIG. 9. - Shape of the luminescence decay time at $77 \mathrm{~K}$ for blue and green bands.

which is consistent with the one found from the intensity quenching (cf. Fig. 4).

The value deduced form the curves $\tau^{-1}(T)$ is much less accurate than from the intensity curve $I(T)$. For the green band, the time constant varia- 


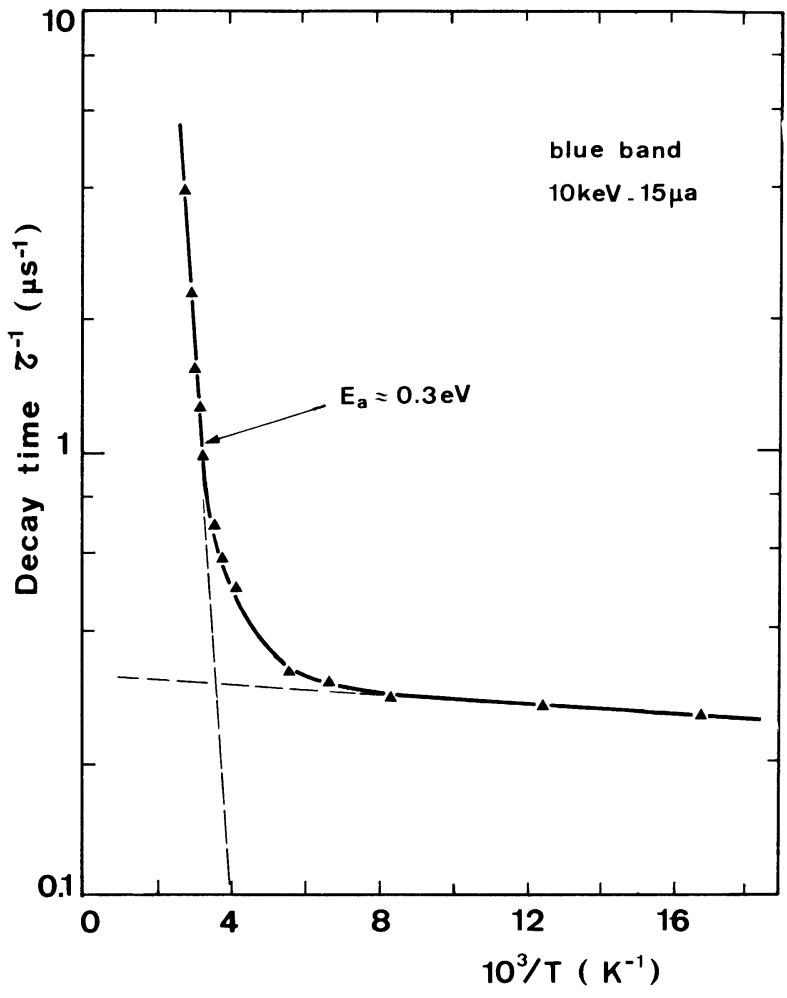

FIG. 10. - Semi-logarithmic recording of the inverse decay time for the blue emission $v s$ reciprocal temperature $10^{3} T^{-1}$.

tions between 77 and $300 \mathrm{~K}$ are smaller, which is also consistent with the intensity variation shown in figure 4.

6. Influence of the injection level. - First, one observes that the maximum of each band shifts towards high energies when the injection current increases, as illustrated by figure 11 for the blue emission. The insert of this figure shows that the short lifetime part of the decay curve is enhanced at high injection level.

The typical variations of the integrated intensity at $300 \mathrm{~K}$ of each band versus injection are shown in figure 12 .

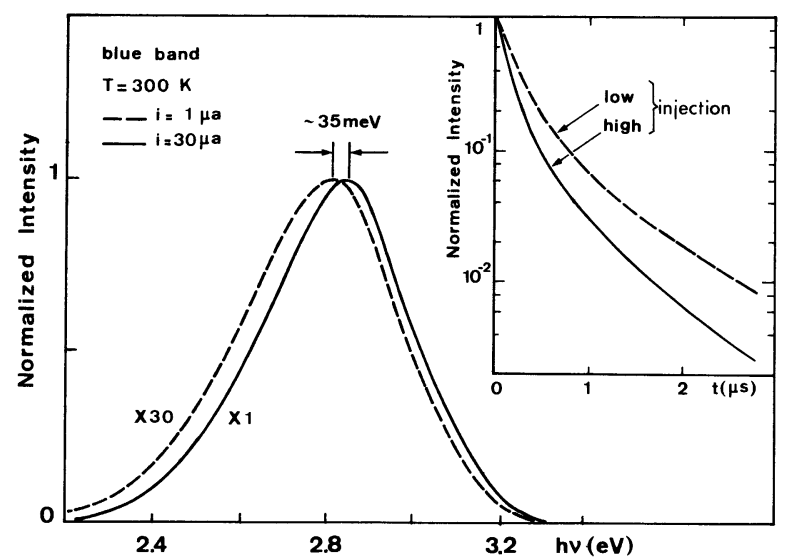

FIG. 11. - Influence of the injection level on the position peak blue emission. The insert of this figure shows the decay time at low and high injection.

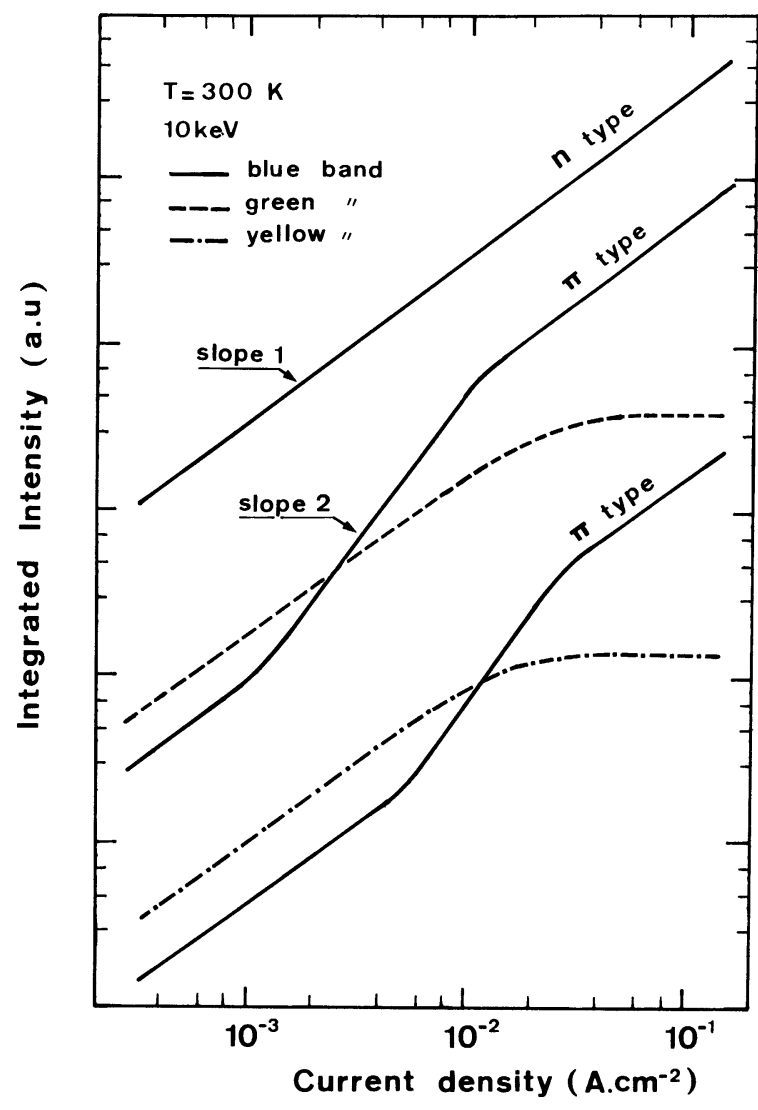

FIG. 12. - Integrated luminescence intensity at $300 \mathrm{~K} v s$ current density injection for three samples with blue ( $n$ type $\left.\mathrm{Zn}=10^{19} \mathrm{~cm}^{-3}\right)$, blue and green $\left(\Pi\right.$ type, $\left.\mathrm{Zn}=6 \times 10^{19} \mathrm{~cm}^{-3}\right)$ blue and yellow (type, $\mathrm{Zn}=10^{20} \mathrm{~cm}^{-3}$ ) emission.

In $n$ type materials, i.e. when the $\mathrm{Zn}$ concentration is not very high, the blue band is observed alone and its intensity varies linearly with the injected current.

On the opposite, semi-insulating $\Pi$ type materials present a more complicated behaviour. When two bands are present, the blue one often shows a superlinear part, while the green or yellow generally saturate at high injection. This situation induces a change of colour when the injection increases, as shown in figure 13 : this sample is first green, then blue. At low temperature (Fig. 14) both the green and blue emissions are linear even when they are present in the same samples.

7. Discussion. - The results described here for the blue, green and yellow emissions are consistent with a pair transition model. (i) The luminescence decays are non-exponential (Figs. 7, 9). (ii) The time resolved spectra show a significant shift of the bands towards lower energies when the delay increases (Fig. 8). (iii) For the blue band, a shift towards higher energies with injection level is observed (Fig. 11). In addition, the peak energies variations versus temperature are close to that of the energy gap.

By pair transitions, we mean here distant transitions, i.e. : donor-acceptor recombination or transition 


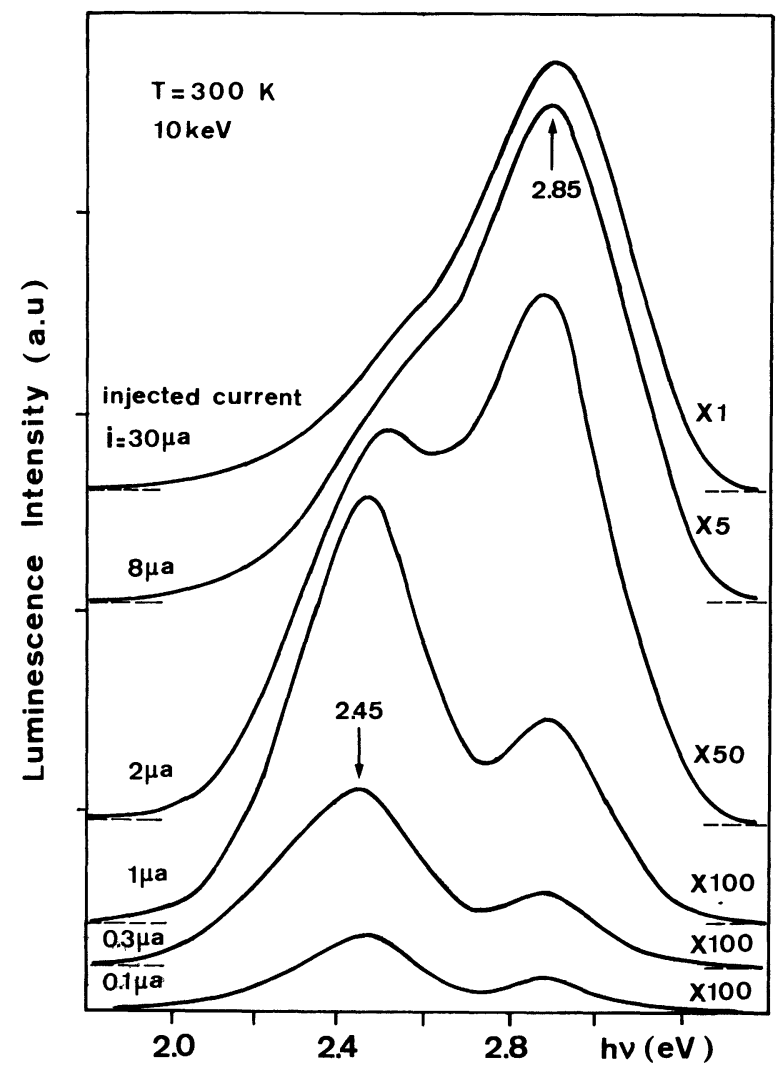

Fig. 13. - CL spectra at $300 \mathrm{~K}$ for different values of injected current.

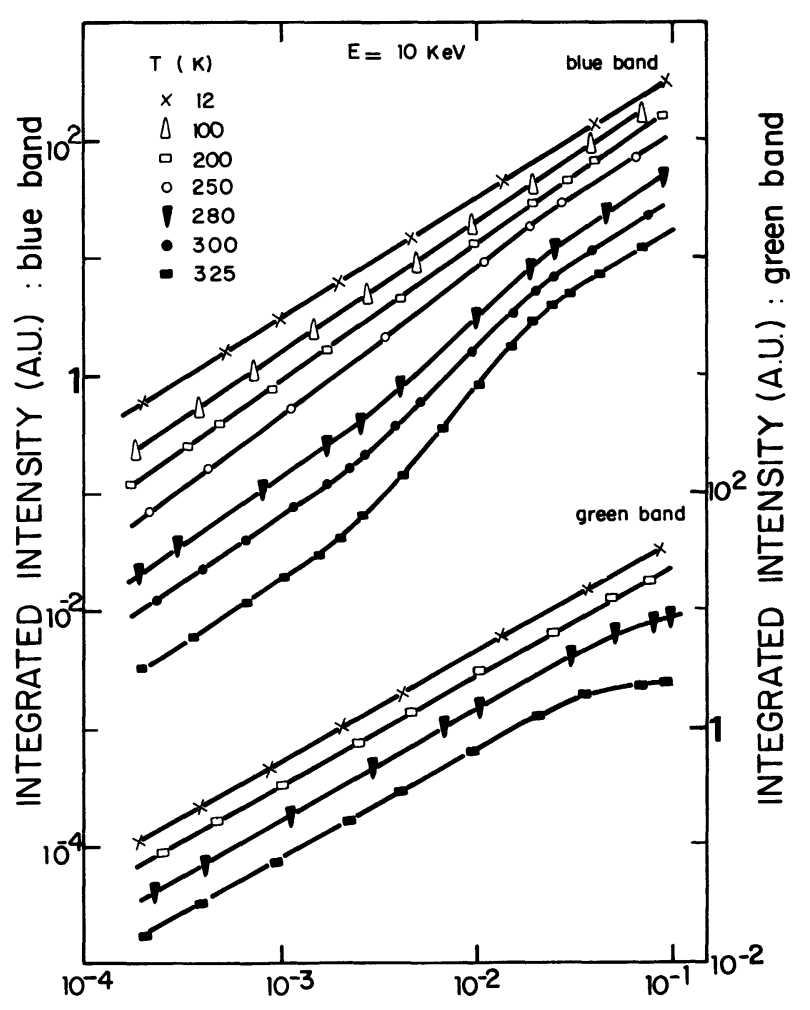

CURRENT DENSITY $\left(A_{-} \mathrm{cm}^{-2}\right)$

Fig. 14. - Dependence temperature of integrated intensity from a $\pi$ type epitaxial layer $\left(\mathrm{Zn}=6 \times 10^{19} \mathrm{~cm}^{-3}\right)$ with blue and green bands $v s$ current density injection. between electrons (or holes) located in conduction band (or valence band), potential walls and a deep centre. Both mechanisms can account for the above mentionned properties, which is not surprising because they are quite similar.

Moreover, potential fluctuations, i.e. : band tailing effect, cannot be neglected in the highly doped materials investigated here. Even, the shallow donor levels in such materials must merge with the conduction band tail, thus, if shallow donors are involved, the two recombination mechanisms cannot be distinguished.

Finally, the recombination processes can be summarized by the model of figure 15 .

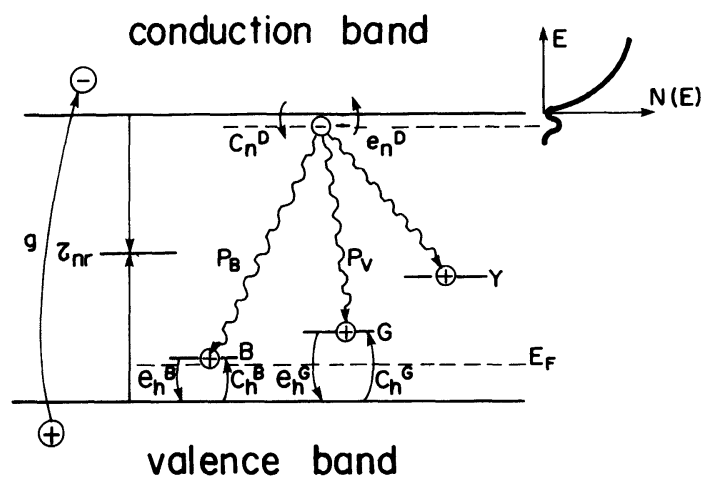

Fig. 15. - Schematic representation at low temperature of recombination processes for $\mathrm{GaN}: \mathrm{Zn}$ in $\Pi$ type material. $\mathrm{D}$ is the donor level and B, V, Y are respectively blue, green and yellow centres. $P_{\mathrm{B}}, P_{\mathrm{G}}$ are the probabilities of transition of these centres. $e_{\mathrm{h}}^{\mathrm{B}}, e_{\mathrm{h}}^{\mathrm{G}}$ and $c_{\mathrm{h}}^{\mathrm{B}}, c_{\mathrm{h}}^{\mathrm{G}}$ are the capture and emission rate of holes for $\mathrm{B}$ and $\mathrm{G}$ centres. $g$ is the generation rate of the electron hole pairs and $\tau_{\mathrm{nr}}$ their non radiative lifetime.

Let us note that the recombinations can occur between the donor band and the deep levels even at $300 \mathrm{~K}$ because the density of states in the donor band is probably very high (comparable with the free carriers density in undoped materials), and the average donor binding energy rather high too $(\sim 42 \mathrm{meV}[37,38])$; therefore this donor band is probably not completly ionized at $300 \mathrm{~K}$.

In $n$ type materials (blue centre alone), the emission intensity $I$ is determined by the hole density on the B level $h_{\mathrm{B}}$ :

$$
I=P_{\mathrm{B}} n_{\mathrm{D}} h_{\mathrm{B}} \quad\left(P_{\mathrm{B}}: \text { transition probability }\right) .
$$

The density of electrons in the donor band $n_{\mathrm{D}}$ depends on the sample only, while $h_{\mathrm{B}}$ can be written :

$$
h_{\mathbf{B}}=\frac{g \tau c_{\mathrm{h}}^{\mathbf{B}} N_{\mathbf{B}}}{g \tau c_{\mathrm{h}}^{\mathbf{B}}+e_{\mathrm{h}}^{\mathbf{B}}+P_{\mathbf{B}} n_{\mathbf{D}}}
$$

$c_{\mathrm{h}}^{\mathrm{B}}$ and $e_{\mathrm{h}}^{\mathrm{B}}$ are the capture and emission rates of holes, $g$ is the density of hole electron pairs created, $\tau$ the injected carrier lifetime, and $N_{\mathbf{B}}$ the level density.

The temperature quenching of the blue lumines- 
cence (cf. 4.1) might then be explained by the hole emission term $e_{\mathrm{h}}^{\mathbf{B}}$, in the high temperature range it becomes larger than the other probabilities.

The activation energy found in section 4.1 would then provide the position of the level above the valence band. In this case, the intensity $I$ varies linearly with the injection level $g$ provided that :

$$
e_{\mathrm{h}}^{\mathrm{B}}+P_{\mathrm{B}} n_{\mathrm{D}} \gg g \tau c_{\mathrm{h}}^{\mathrm{B}}
$$

in agreement with the experimental results of section 6 , this condition is verified in $n$ type sample $\left(n_{\mathrm{D}}\right.$ being large).

In $\Pi$ type materials, with for instance blue (B) and green $(G)$ centres present, we must take into account

(i) The variation of $n_{\mathrm{D}}$ :

$$
n_{\mathrm{D}}=\frac{g \tau c_{\mathrm{n}} N_{\mathrm{D}}}{g \tau c_{\mathrm{n}}^{\mathrm{D}}+e_{\mathrm{n}}^{\mathrm{D}}+P_{\mathrm{B}} h_{\mathrm{B}}+P_{\mathrm{G}} h_{\mathrm{G}}}
$$

where $c_{\mathrm{n}}^{\mathrm{D}}$ and $e_{\mathrm{n}}^{\mathrm{D}}$ are the capture and emission rates for the D level, $N_{\mathrm{D}}$ its density, and $P_{\mathrm{G}}, h_{\mathrm{G}}$ are respectively the transition probability and the density of holes from $\mathrm{G}$ level.

(ii) The variation of $h_{\mathrm{B}}$ :

$$
h_{\mathbf{B}}=h_{\mathrm{BO}}+\delta h_{\mathrm{B}}=\frac{(g \tau+h) c_{\mathrm{h}}^{\mathbf{B}} N_{\mathrm{B}}}{(g \tau+h) c_{\mathrm{h}}^{\mathbf{B}}+e_{\mathrm{h}}^{\mathbf{B}}+P_{\mathrm{B}} n_{\mathrm{D}}}
$$

$h$ being the density of holes in the valence band, $h_{\text {BO }}$ the density of holes from the centre B at thermal equilibrium and $\delta h_{\mathrm{B}}$ the injected holes.

(iii) The variation of $h_{\mathrm{G}}$ for the green centre which is similar :

$h_{\mathrm{G}}=h_{\mathrm{GO}}+\delta h_{\mathrm{G}}=\frac{(g \tau+h) c_{\mathrm{h}}^{\mathrm{G}} N_{\mathrm{G}}}{(g \tau+h) c_{\mathrm{h}}^{\mathrm{G}}+e_{\mathrm{h}}^{\mathrm{G}}+P_{\mathrm{G}} n_{\mathrm{D}}}$.

In $\Pi$ type materials, the Fermi level can be assumed to lie in the lower part of the forbidden band, thus $h_{\mathrm{BO}}$ and $h_{\mathrm{GO}}$ are likely to be non negligible. The intensity variations versus injection (Figs. 12, 14) can be explained if one assumes the Fermi level to lie below the blue level at low temperature, so that $h_{\mathrm{BO}} \simeq N_{\mathrm{B}}$ and $h_{\mathrm{GO}} \simeq N_{\mathrm{G}}$ at low temperature. Thus, the recombination processes are limited by the electron density on the donor levels $n_{\mathrm{D}}$, which leads to a linear variation for both bands in the whole injection range analysed here. At high temperature $(300 \mathrm{~K})$, as demonstrated in section $4.1, e_{\mathrm{h}}^{\mathbf{B}}$ is non negligible; therefore $0<h_{\mathrm{BO}}<N_{\mathrm{B}}$. At low injection, one finds again a linear variation provided that $\delta h_{\mathrm{B}} \ll h_{\mathrm{BO}}$. But, at higher injection $\delta h_{\mathrm{B}}$ may become larger than $h_{\mathrm{BO}}$, as it is roughly proportional to the injection $g$, the intensity $I \alpha P_{\mathrm{B}} n_{\mathrm{D}} \delta h_{\mathrm{B}}$ varies as $g^{2}$ as observed in figure 12 . For the highest excitation levels, saturation appears for the green emission while the blue becomes linear again. This can be understood by the saturation of the distant pairs.

4. Conclusion. - Three main emission bands are found in gallium nitride doped with zinc : blue at $2.85 \mathrm{eV}$, green at $2.5 \mathrm{eV}$ and yellow at $2.2 \mathrm{eV}$. Their introduction is well correlated with the real amount of zinc incorporated in the layers. A weaker emission has also been observed sometimes in the red $(1.9 \mathrm{eV})$ in the highly doped materials.

For the blue and green, thermally actived quenching is observed. It is supposed to correspond to hole reemission out of the blue and green centres at high temperature. At room temperature the hole emission rate out of the blue levels is non negligible; this indicates that holes must be present in the valence band at room temperature. This interpretation is in agreement with the results of electrical analysis which show that $\Pi$ type conductivity is attained $[9,19]$.

The luminescence decays are non-exponential, time resolved spectra shift towards lower energies as the delay increases, and a shift towards higher energies is observed as the injection increases. This is in favour of a pair transition model.

The variations of the integrated intensities versus injection can also be explained with such a model provided that the Fermi level at low temperature is located below the blue level in the $\Pi$ type materials.

The analysis of the temperature behaviour of the shape of the bands has shown that phonon coupling does occur. This situation is very close to the one found in GaP where pairs transitions strongly coupled with phonons are also observed [39]. Because of this phonon coupling, one cannot in a simple way, locate the energy levels involved in the forbidden band. This can be better done using the thermal activation energies deduced from the emission quenching, i.e. : $0.3 \mathrm{eV}$ for the blue band, 0.8 . eV for the green and a higher value for the yellow.

The exact nature of the centres responsible for these emissions are not yet known but however, one can assume that complexes are formed of $\mathrm{Zn}$ atoms and $\mathrm{N}$ vacancies involving one, two to three $\mathrm{Zn}$ atoms and one nitrogen vacancy which are expected to have three unstable electrons $\left(V_{\mathrm{N}}: \mathrm{Zn}, V_{\mathrm{N}}: 2 \mathrm{Zn}, V_{\mathrm{N}}: 3 \mathrm{Zn}\right)$ both being present with high concentration in the material.

Acknowledgments. - The authors wish to thank M. Furtado, J. Hallais, L. Hollan for helpful discussions and A. Mircea, C. Schiller for their fruitful discussions. 


\section{References}

[1] Pankove, J. Lumin. 7 (1973) 114.

[2] Pankove, J. I., R.C.A. Revue 34 (1973) 336.

[3] Maruska, H. P., Stevenson, P. A., Solid State Electron 17 (1974) 1971

[4] Jacob, G., Madar, R., Hallais, J., Mat. Res. Bull. 11 (1976) 445.

[5] Shintani, A., Minagawa, S., J. Electrochem. Soc. 123 (1976) 1575.

[6] Мовiмoto, Y., Ushio, S., Jap. J. Appl. Phys. 13 (1974) 365.

[7] JaCOB, G. and BoIs, D., Appl. Phys. 30 (1977) 412.

[8] Jacob, G., Boulou, M., Furtado, M., J. Crystal Growth 42 (1977) 136.

[9] JaCOB, G., Boulou, M., Furtado, M. and Bois, D., presented at 19th Electronic Materials Conf., Ithaca NY, and published in J. Electronic Mat. 7 (1978) 499.

[10] Madar, R., Michel, D., Jacob, G. and Boulou, M., $J$. Crystal Growth 40 (1977) 239.

[11] Ilegems, M., Dingle, R. D. and Logan, R. A., J. Appl. Phys. 43 (1972) 3797.

[12] Pankove, J. I., J. Lumin. 5 (1972) 482.

[13] Pankove, J. I. and Hutchby, J. A., J. Appl. Phys. 47 (1976) 5387.

[14] Pankove, J. I., Bloom, S., Harbeke, G., R.C.A. Rev. 36 (1975) 163.

[15] Ejder, E., Grimmeiss, H. G., Appl. Phys. 5 (1974) 275.

[16] Suleimanov, Yu. M., Pichugin, J. G. and Marasina, L. A., Sov. Phys. Semicond. 8 (1974).

[17] Pankove, J. I., Miller, E. A. and Berkeyheiser, J. E., $J$. Lumin. 5 (1972) 84.

[18] Nickl, J. J., Just, W. and Bertinger, R., Mat. Res. Bull. 10 (1975) $1097-1104$

[19] JACOB, G., Boulou, M., Bois, D., to be published in J. Lum. (1978).

[20] Maruska, H. P., Tietjen, J: J., Appl. Phys. Lett. 15 (1969) 327.

[21] Cunningham, R. D., Brander, R. W., Knee, N. D. and WICKENDEN, D. K., J. Lumin. 5 (1972) 21.

[22] Grimmeiss, H. G. and Monemar, B., J. Appl. Phys. 41 (1970) 4054.
[23] Lagerstedt, O. and Monemar, B., J. Appl. Phys. 45 (1974) 2266.

[24] Marasina, L. A., PJkhtun, A. N., Pichugin, I. G. and SoloMONoy, A. V., Phys. Status Solidi (a) 38 (1976) 753.

[25] Ilegems, M., Dingle, R., Logan, R. A., J. Appl. Phys. 43 (1972) 3797.

[26] Vasilishchev, A. N., Mikhailov, L. N., Sidorov, V. G., Shagalov, M. D., Shalabutov, Y. K., Sov. Phys. Semicond. 9 (1975) 1189.

[27] Shintani, A., Minagawa, S., Electrochem. S. 123 (1976) 1725.

[28] Pankove, J. I., Berkeyeiser, J. E., Miller, E. A., J. Appl. Phys. 45 (1974) 1280.

[29] Matsumoto, T., Sano, M., Aoki, M., Jpn. J. Appl. Phys. 13 (1974) 373.

[30] Ilegems, M., Dingle, R., J. Appl. Phys. 44 (1973) 4234.

[31] Pankove, J. I., Berkeyheiser, J. E., J. Appl. Phys. 45 (1974) 3892.

[32] Kuick, C. C. and Schulman, J. H., Solid State Phys. edited by F. Seitz and D. Turnbull (Academic Press Inc. New York, 1957), vol. 5 p. 100 gives a view of the application of the configurational coordinate model to luminescence.

[33] Barker Jr, A. S. and Ilegems, M., Phys. Rev. B 7 (1973) 743.

[34] Manchon Jr, D. D., Barker Jr, A. S., Dean, P. J. and Ze rTERSTROM, R. B., Solid State Commun. 8 (1970) 12281231.

[35] Boulou, M., Bois, D., J. Appl. Phys. 48 (1977) 4713.

[36] Pankove, J. I., Maruska, H. P. and Berkeyheiser, J. E., in Proceedings of the 10th International Conference on Physics of Semiconductors (U.S. Atomic Energy Commission, Washington, D.C., 1970) p. 593.

[37] Dingle, R., Sell, D. D., Stokowski, S. E. and Ilegems, M., Phys. Rev. B4 (1971) 1211.

[38] Dingle, R. and Ilegems, M., Solid. State Commun. 9 (1971) 175.

[39] Vink, A. T., van der Heyden, R. L. A. and van Amstel, A. C., J. Lumin. 9 (1974) 180-211. 